\title{
PENGARUH RELIGIUSITAS TERHADAP PERENCANAAN KARIR MAHASISWA UIN SUSKA RIAU DENGAN EFIKASI DIRI SEBAGAI VARIABEL INTERVENING
}

\author{
Hariza Hasyim \\ Universitas Islam Negeri Sultan Syarif Kasim Riau \\ hariza.hasyim@uin-suska.ac.id
}

\begin{abstract}
This study aims to see the effect of religiosity on career planning of UIN Suska Riau students by using self-efficacy as an intervening variable. This study used primary data in the form of a questionnaire given to 2407 th semester students of UIN Suska Riau. The analysis was carried out using descriptive statistical analysis and hypothesis testing analysis with the Structural Equation Model (SEM), PLS 28. Descriptively, the level of self-efficacy, level of religiosity, and level of career planning of UIN Suska Riau students were at a moderate level. From the results of hypothesis testing, it was found that religiosity had a positive and significant direct effect on the self-efficacy of UIN Suska Riau students. Self-efficacy has a positive and significant direct effect on planning. Religiosity has a positive and significant direct and indirect effect on career planning for UIN Suska Riau students. Religiosity through self-efficacy will improve the career planning of UIN Suska Riau students.
\end{abstract}

Keywords: Self-efficacy, religiosity, career planning

\begin{abstract}
ABSTRAK
Penelitian ini bertujuan untuk melihat pengaruh religiusitas terhadap perencanaan karir mahasiswa UIN Suska Riau dengan menggunakan efikasi diri sebagai variabel intervening.. Penelitian ini menggunakan data primer yaitu berupa kuesioner yang diberikan kepada 240 orang mahasiswa semester 7 UIN Suska Riau. Analisis yang dilakukan dengan menggunakan analisis statistik deskriptif dan dengan analisis pengujian hipotesis dengan Struktural Equation Model (SEM) , PLS 28. Secara deskriptif tingkat efikasi diri, tingkat religiusitas, dan tingkat perencanaan karir dari mahasiswa UIN Suska Riau, berada pada level sedang. Dari hasil pengujian hipotesis diperoleh bahwa religiusitas berpengaruh positif dan signifikan secara langsung terhadap efikasi diri mahasiswa UIN Suska Riau. Efikasi diri berpengaruh positif dan signifikan secara langsung terhadap perencanaan. Religiusitas berpengaruh positif dan signifikan secara langsung dan tidak langsung terhadap perencanaan karir mahasiwa UIN Suska Riau. Religiusitas melalui efikasi diri akan meningkatkan perencanaan karir mahasiwa UIN Suska Riau.
\end{abstract}

Kata Kunci: Efikasi diri, religiusitas, perencanaan karir 
PENDAHULUAN

\section{Latar Belakang Masalah}

Lulusan Perguruan Tinggi di Indonesia saat ini mengalami dilema. Ijazah sarjana yang diperoleh tidak lagi menjadi jaminan dalam mudahnya mendapatkan pekerjaan. Persaingan bukan lagi people to people, tapi sudah pada kecanggihan teknologi. Sebagai konsekuensi dari semakin berkembangnya pengetahuan dan teknologi, munculnya revolusi industri 4.0, telah berdampak pada penggunanan jumlah tenaga kerja dalam proses produksi dan pekerjaan makin lama akan makin berkurang.

Persaingan dunia kerja yang semakin berat mengharuskan para calon tenaga kerja, berjuang untuk dapat diterima didalam pasar kerja. Dengan jumlah pesaing yang banyak, yang diterima bekerja hanya sebagian kecil saja, maka hanya akan meloloskan tenaga kerja yang memiliki kemampuan dan kompetensi tinggi. Indonesia menempati peringkat ketiga setelah India dan Brasil sebagai negara dengan pertumbuhan lulusan universitas terbanyak, yaitu lebih dari 4 persen dan rata-rata surplus 1.5 persen per tahun.

Perguruan Tinggi sebagai wadah utama bagi mahasiswa untuk mendalami program studi yang telah dipilihnya, agar mereka memiliki keahlian, kemampuan dan kecakapan sesuai program studi pilihan mereka. Sehingga mereka akan siap bersaing dalam dunia kerja di bidang pekerjaan yang diminati setelah lulus dari perguruan tinggi. Bagi mahasiswa yang sudah memasuki semester akhir, pilihan program studi yang mereka ambil seharusnya bukan lagi merupakan pilihan yang asal-asalan atau hanya mengikuti trend belaka, melainkan suatu pilihan yang diambil berdasarkan minat, bakat dan keputusan bersama antara mahasiswa dan orang tuanya.

Perencanaan karir merupakan proses berkelanjutan dimana seseorang menetapkan tujuantujuan karir dan mengidentifikasikan cara-cara untuk mencapainya. Dalam mencapai rencana karirnya, individu memerlukan usaha-usaha yang besar. Bandura (dalam Pinasti, 2011) mengungkapkan bahwa orang yang memiliki efikasi diri yang tinggi, akan mengeluarkan usaha yang besar untuk mengatasi hambatan dalam mencapai tujuannya. Selain itu efikasi diri merujuk pada tingkat kepercayaan diri individu dan keyakinannya akan kemampuannya terhadap kesuksesan, sehingga memunculkan suatu perbuatan, menunjukkan perilaku yang diinginkan, menyelesaikan pekerjaan yang diberikan, dan mencapai prestasi yang diinginkan. Karena memiliki keyakinan akan kemampuan yang dimilikinya, mahasiswa akan merasa mampu 
dalam menghadapi dunia kerja. Sebaliknya, mahasiswa yang mempunyai keyakinan terhadap kemampuan yang dimilikinya rendah, maka dirinya akan kurang merasa mampu dalam menghadapi dunia kerja.

Dalam konteks perencanaan karir oleh individu, terdapat beberapa faktor yang mempengaruhi individu dalam memilih suatu karir atau pekerjaan. Salah satu faktor tersebut adalah nilai-nilai yang dianut. Faktor-faktor dalam diri individu yang memengaruhi pembentukan pilihan terhadap pekerjaan di antaranya adalah kecerdasan, minat, bakat, sikap, kepribadian, dan nilai. Nilai merupakan suatu yang diharapkan (das solen) oleh manusia. Nilai merupakan sesuatu yang baik yang dicitakan manusia.

Nilai-nilai religius adalah salah satu nilai yang menjadi dasar berperilaku terutama individu. Saat ini, terdapat banyak orang menaruh minat pada agama dan menganggap bahwa agama berperan penting dalam kehidupan. Minat pada agama antara lain tampak dengan membahas masalah agama, mengikuti pelajaran-pelajaran agama di sekolah dan di perguruan tinggi, dan mengikuti berbagai acara keagamaan.

Universitas Islam Sultan Syarif Kasim (UIN Suska), adalah salah satu Perguruan Tinggi Negri Islam, di Indonesia, dengan kompetensi keislaman sebagai ciri khas. Program Universitas yang mencakup dua aspek: Aspek penanaman dan pengamalan nilai-nilai Keislaman; Aspek penguasaan satu atau beberapa cabang studi Keislaman.

Dari uraian yang peneliti sampaikan di atas, peneliti ingin mengetahui lebih lanjut dengan melakukan penelitian yang diberi judul Pengaruh Religiusitas terhadap Perencanaan Karir Mahasiswa UIN Sultan Syarif Kasim Riau dengan Efikasi Diri sebagai Variabel Intervening

\section{Tujuan Penelitian}

a. Untuk menguji dan menganalisis seberapa besar pengaruh religiusitas terhadap efikasi diri mahasiswa UIN Suska Riau?

b. Untuk menguji dan menganalisis seberapa besar pengaruh efikasi diri terhadap perencanaan karir mahasiswa UIN Suska Riau?

c. Untuk menguji dan menganalisis seberapa besar pengaruh religiusitas terhadap perencanaan karir mahasiswa UIN Suska Riau?

d. Untuk menguji dan menganalisis seberapa besar pengaruh religiusitas melalui efikasi diri 
terhadap perencanaan karir mahasiswa UIN Suska Riau?

\section{Manfaat Penelitian}

a. Pengembangan kajian penelitian selanjutnya dalam bidang perencanaan karir mahasiswa, efikasi diri mahasiswa, religiusitas mahasiswa.

b. Sebagai referensi bagi penelitian-penelitian yang akan datang dalam konteks permasalahan yang berkaitan dengan perencanaan karir mahasiswa, efikasi diri mahasiswa, dan religiusitas mahasiswa.

c. Bagi UIN Sultan Syarif Kasim Riau, diharapkan hasil penelitian ini dapat menjadi tambahan informasi dalam membuat kebijakan perencanaan peningkatan sumberdaya manusia khususnya dalam menyiapkan mahasiswa yang memiliki perencanaan karir, religiusitas dan efikasi diri yang lebih baik.

d. Manfaat praktis bagi mahasiswa, yaitu sebagai pedoman untuk meningkatkan perencanaan karir dari aspek efikasi diri, dan religiuisitas

\section{Urgensi Penelitian}

Penelitian ini penting, mengingat saat ini kondisi pengangguran dan pemutusan hubungan kerja (PHK) yang semakin meningkat. Konsep diri yang diyakini dari beberapa penelitian terdahulu memilki pengaruh terhadap perencanaan karir, perlu mendapatkan perhatian dari mahasiswa yang akan menamatkan perguruan tinggi. Memberikan perhatian terhadap aspek religi, diharapkan akan memberikan pengaruh yang besar dan baik terhadap aspek lain dari sisi kehidupan manusia. Dengan memperhatikan aspek religisitas dari mahasiswa, akan meningkatkan konsep efikasi diri dari mahasiswa, dan pada akhirnya membuat mereka memiliki perencanaan karir yang lebih baik.

\section{Tinjauan Literatur}

\section{Religiusitas}

Agama, dalam hal ini adalah Islam berasal dari kata-kata: salam yang berarti damai dan aman salamah berarti selamat istilah islam sendiri berarti penyerahan diri secara mutlak kepada Allah SWT untuk memperoleh ridho-Nya dengan mematuhi perintah dan meninggalkan laranganNya. Islam adalah satu-satunya agama yang benar dan dibenarkan serta diakui oleh Allah SWT, Sesuai dengan Firman Allah QS. Ali Imran ayat 85 sebagai berikut: 


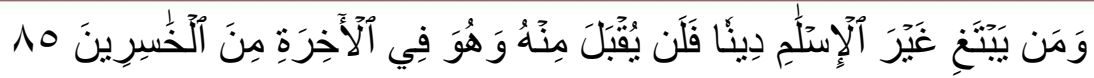

Artinya: Barangsiapa mencari agama selain agama Islam, maka sekali-kali tidaklah akan diterima (agama itu)daripadanya, dan dia di akhirat termasuk orang-orang yang rugi

Religius menurut Islam adalah menjalankan ajaran agama secara menyeluruh. Allah berfirman dalam Al-Qur'an surat Al-Baqarah-208:

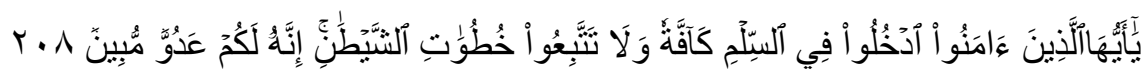

Artinya: Hai orang-orang yang beriman, masuklah kamu ke dalam Islam keseluruhan, dan janganlah kamu turut langkah-langkah syaitan. Sesungguhnya syaitan itu musuh yang nyata bagimu.

Agama menuntun perjalan hidup manusia agar tetap berada diatas jalan lurus (shirotol mustaqim) yang diridhai oleh Allah SWT. Menurut hukum Islam, agama berfungsi sebagai sarana untuk mengatur sebaik mungkin dan memperlancar proses interaksi sosial sehingga terwujudnya masyarakat yang harmonis, aman, dan sejahtera. Fetzer juga mendefinisikan religiusitas adalah sesuatu yang lebih menitikberatkan pada masalah perilaku, sosial, dan merupakan sebuah doktrin dari setiap agama atau golongan. Doktrin yang dimiliki oleh setiap agama wajib diikuti oleh setiap pengikutnya.

Religiusitas dianggap dapat meredakan kecemasan yang terjadi pada seseorang. Karena dengan adanya religiusitas seseorang mempunyai pegangan atau keyakinan yang kuat terhadap apa yang akan terjadi pada kehidupan manusia semata- mata adalah takdir Tuhan.

\section{Efikasi Diri}

Istilah efikasi diri pertama kali diperkenalkan oleh Bandura dalam Psychological Review nomor 84 tahun 1986. Bandura mengemukakan self-efficacy is "the belief in one's capabilities to organize and execute the courses of action required to manage prospective situations". Pada intinya bahwa efikasi diri mengacu pada keyakinan sejauhmana individu memperkirakan kemampuan dirinya dalam melaksanakan tugas atau melakukan suatu tugas yang diperlukan untuk mencapai suatu hasil tertentu. Bandura juga menyatakan bahwa efikasi diri merupakan sejumlah perkiraan tentang kemampuan yang dirasakan seseorang.

Pikiran individu terhadap efikasi diri menentukan seberapa besar usaha yang akan dicurahkan dan seberapa lama individu akan tetap bertahan dalam menghadapi hambatan atau pengalaman yang tidak menyenangkan. 
Efikasi diri yang dimiliki seseorang berbeda-beda, dapat dilihat berdasarkan aspek yang mempunyai implikasi penting pada perilaku. Ada tiga aspek dalam efikasi diri yaitu:

1) Magnitude. Aspek ini berkaitan dengan kesulitan tugas.

2) Generality. Aspek ini berhubungan luas bidang tugas atau tingkah laku.

3) Strength. Aspek ini berkaitan dengan tingkat kekuatan atau kemantapan seseorang terhadap keyakinannya.

\section{Perencanaan Karir}

Perencanaan berasal dari kata rencana, yaitu pengambilan keputusan tentang apa yang harus dilakukan untuk mencapai tujuan. Perencanaan karir adalah proses berkelanjutan dimana seseorang menetapkan tujuan - tujuan karir dan mengidentifikasi cara - cara untuk mencapainya. Perencanaan karir juga didefenisikan sebagai serangkaian kegiatan yang dilakukan orang dalam menentukan arah karir mereka pada waktu berikutnya. Proses ini biasanya mencangkup tinjauan pribadi atas pengalaman, keterampilan dan nilai seseorang, menjelaskan sasaran-sasaran karir, serta menemukan cara dalam mengimplementasikan gagasan-gagasan perubahan dan perkembangannya.

Perencanaan karier (career planning) adalah suatu proses dimana individu dapat mengidentifikasi dan mengambil langkah-langkah untuk mencapai tujuan- tujuan karir. Perencanaan karir melibatkan pengidentifikasian tujuan- tujuan yang berkaitan dengan karir dan penyusunan rencana-rencana untuk mencapai tujuan tersebut. Dalam proses perencanaan karir individu akan memperoleh pengetahuan tentang potensi yang ada pada diri yang meliputi keterampilan, minat, pengetahuan, motivasi, dan karakteristik yang digunakan sebagai dasar dalam pemilihan karir yang kemudian dilanjutkan dengan menentukan tahapan untuk bisa mencapai karir yang sudah dipilih.

Selain itu, perencanaan karir didefenisikan oleh Werner dan Desimone sebagai berikut:

Career planning is a deliberate process of (1) becoming aware of self, opportunities, constraints, choices, and consequences, (2) identifying career-related goals, (3) programming work, education, and related-developmental experiences to provide the direction, timing, and sequence of steps to attain a specific career goal.Perencanaan karir merupakan proses (1) menjadi sadar terhadap diri sendiri, peluang, kendala, pilihan, dan konsekuensi, (2) mengidentifikasi tujuan yang terkait dengan karir, (3) memprogram pekerjaan, pendidikan, pengalaman 
pengembangan yang terkait untuk memberi arah, timing, dan urutan langkah untuk mencapai tujuan karir khusus. Ditinjau dari deskripsi tersebut, perencanaan karir merupakan kemampuan individu dalam memahami dan berusaha mengendalikan kehidupan kerjanya sendiri. Perencanaan karir merupakan

A. Kerangka Pemikiran

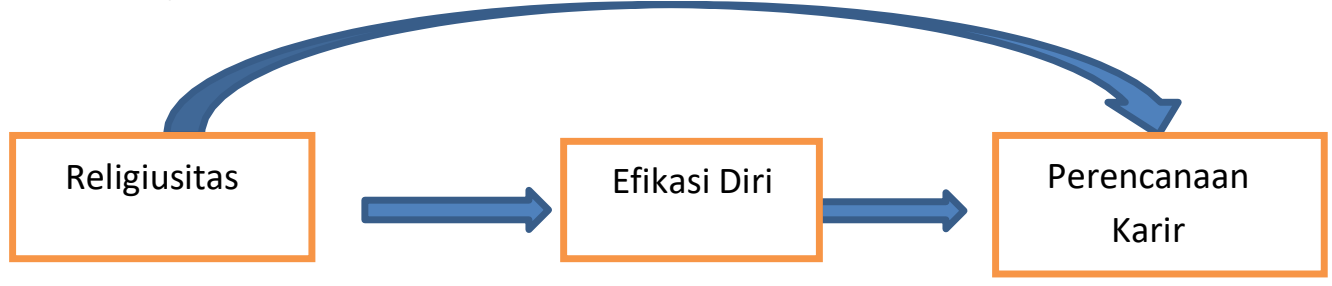

Efikasi Diri, bertindak sebagai variabel Intervening, yaitu menjadi variabel antara, dari religiusitas sebgai variabel bebas ke variabel tidak bebas dalam hal ini perencanaan karir.

\section{Defenisi Operasional Variabel dan Indikator penelitian}

\begin{tabular}{|c|c|c|c|}
\hline No & Variabel & Defenisi Operasional & Indikator \\
\hline 1 & $\begin{array}{l}\text { Religiusitas } \\
\text { (X1) }\end{array}$ & $\begin{array}{l}\text { Merupakan seberapa jauh } \\
\text { pengetahuan, seberapa kokoh } \\
\text { keyakinan, seberapa pelaksanaan } \\
\text { ibadah dan kaidah dan seberapa } \\
\text { dalam penghayatan atas agama } \\
\text { yang dianut seseorang }\end{array}$ & $\begin{array}{l}\text { 1. Daily Spiritual } \\
\text { Experiences, } \\
\text { 2. Values } \\
\text { 3. Beliefs, } \\
\text { 4. Forgiveness } \\
\text { 5. PrivatenReligious } \\
\text { Practices } \\
\text { 6. Religious/Spiritual } \\
\text { Coping. } \\
\text { 7. Religious Support, } \\
\text { 8. Religious/Spiritual } \\
\text { History, } \\
\text { 9. Organizational } \\
\text { Religiusnes }\end{array}$ \\
\hline 2 & $\begin{array}{l}\text { Efikasi } \\
(\mathrm{Z} 1)\end{array}$ & $\begin{array}{lr}\text { Merupakan keyakinan seseorang } \\
\text { terhadap kemampuan yang } \\
\text { dimilikinya } & \text { untuk } \\
\text { mengorganisasikan } & \text { dan } \\
\text { melaksanakan } & \text { serangkaian } \\
\text { tindakan yang harus dilakukan } \\
\text { untuk menghasilkan tujuan yang } \\
\text { ditetapkan }\end{array}$ & $\begin{array}{l}\text { 1. Magnitude } \\
\text { 2. Generally } \\
\text { 3. Strength }\end{array}$ \\
\hline
\end{tabular}




\begin{tabular}{|l|l|lr|l|}
\hline 3 & Perencanaan & Suatu proses & berkelanjutan & 1. Penilaian diri \\
& Karir (Y) & dimana & seseorang & menetapkan \\
& tujuan-tujuan & dan & 2. Mengidentifikasi \\
& karir \\
& mengidentifikasi & cara-cara \\
& mencapainya & & 3. Perencanaan \\
& & & $\begin{array}{l}\text { aktivitas } \\
\text { pengembangan }\end{array}$ \\
& & & \\
\hline
\end{tabular}

\section{Hipotesa yang hendak diuji adalah:}

H1: Terdapat pengaruh langsung religiusitas terhadap efikasi diri Mahasiswa UIN Suska UINSuska Riau

H2: Terdapat pengaruh langsung efikasi diri terhadap perencanaan karir

H3: Terdapat pengaruh langsung religiuistas terhadap perencanaan karir mahasiswa UIN Suska Riau

H4: Terdapat pengaruh tidak langsung religiusitas terhadap perencanaan karir melalui efikasidiri sebagai variabel intervening pada mahasiswa UIN Suska Riau

\section{Penelitian Terdahulu}

1. Duffy, R. D.,\& Sedlacek, W. E. (2010) melihat sejauh mana mahasiswa tahun pertama mendukung panggilan karir dan bagaimana tingkat panggilan berbeda di antara variabel demografis dan religius, makna hidup, dan kepuasan hidup. Penelitian tersebut mengungkapkan bahwa individu dengan religiusitas yang tinggi, lebih percaya diri dan berkomitmen terhadap keputusan karir yang mereka buat. Penelitian tersebut juga mengungkapkan bahwa individu yang terafiliasi dalam suatu komunitas keagamaan yang suportif memiliki efikasi diri yang tinggi terkait dengan keputusan dalam karir. Bagi individu yang telah bekerja, individu yang memiliki dukungan sosial yang suportif dari komunitas keagamaan lebih mampu mengatasi masalah ketika individu tersebut mengalami stress kerja atau kehilangan pekerjaan. Individu tersebut lebih sedikit mengalami depresi dan tidak kehilangan harapan .

2. Pada penelitian yang dilakukan oleh Marliani (2014) mengenai Hubungan antara Religiusitas dengan Orientasi Masa Depan dalam Bidang Pekerjaan, terdapat korelasi positif antara tingkat religiusitas dengan orientasi masa depan pada bidang pekerjaan. Penelitian dilakukan di Universitas Islam Negeri Sunan Gunung Djati Bandung terhadap mahasiswa tingkat akhir 
fakultas Ushuluddin. Melalui Penelitian tersebut, diketahui sebanyak 52.4 \% (33 orang) mahasiswa memiliki tingkat religiusitas tinggi dan $47.6 \%$ (30 orang) mahasiswa memiliki tingkat religiusitas rendah. Mahasiswa yang memiliki tingkat religiusitas tinggi (52.4\% atau 33 orang), memiliki tingkat orientasi masa depan dalam bidang pekerjaan yang jelas. Sedangkan mahasiswa yang memiliki tingkat religiusitas rendah (47.6\% atau 30 orang) memiliki tingkat religiusitas kurang jelas. Hal ini membuktikan bahwa terdapat hubungan antara tingkat religiusitas dengan orientasi masa depan dalam bidang pekerjaan.

3. Khairul Amri Wicaksono, meneliti Hubungan antara self Efficacy dengan self Regulation dengan perencanaan Karir pada Mahasiswa Semester 8 UNS Semarang. Penelitian ini merupakan penelitian kuantitatif dengan metode korelasional dengan teknik analisis regresi dua prediktor. Subjek penelitian ini mahasiswa, semester 8 Universitas Negeri Semarang, berjumlah 179 orang. Hasil penelitian menunjukan bahwa perencanaan karir dan self-efficacy mahasiswa semester 8 Universitas Negeri Semarang pada kategori baik dengan mean empiris 162,4022 dan 77,9777. Sedangkan, self-regulation pada kategori cukup baik dengan mean empiris 95,3966. Hasil analisis pertama diperoleh thitung 11,319 dengan signifikansi $0,000<0,01$. Artinya, Self-efficacy memiliki hubungan yang positif dan signifikan dengan perencanaan karir pada mahasiswasemester 8 Universitas Negeri Semarang. Besarnya sumbangan self-efficacy terhadap perencanaan karir sebesar $41,7 \%$.

\section{METODE PENELITIAN}

\section{Jenis Penelitian}

Jenis penelitian ini adalah penelitian survey dengan data dan pengolahan secara kuantitatif. Menggunakan penelitian survey karena dalam pengumpulan data penulis menghimpun informasi dari para responden menggunakan kuesioner sebagai metode pokok. Penelitian survey adalah penelitian yang mengambil sampel dari satu populasi dan menggunakan kuesioner sebagai alat pengumpulan data yang pokok

\section{Populasi dan Sampel Penelitian}

Secara umum, ukuran sampel untuk model persamaan struktural paling sedikit 200 pengamatan (Kelloway, 1998 dalam Bacharuddin dan Harapan, 2003 : 68). Sedangkan pendapat Hair, Aderson, Tatham dan Black dalam Kusnendi (2005) yang menyarankan ukuran sampel minimal untuk analisis SEM adalah 100 sampai 200. 
Dalam penelitian ini, Sampel berasal dari mahasisiswa UIN Suska yang sedang duduk di semester VII, pada tahun 2019. Responden tersebar pada delapan Fakultas yang ada di UIN Sultan Syarif Kasim, Riau. dan setiap mahasiswa semester 7 memiliki peluang yang sama menjadi sampel dalam penelitian ini. Tabel 1 Populasi dan Sampel Penelitian

\begin{tabular}{llll}
\hline No & \multicolumn{1}{c}{ Fakultas } & Populasi & Perhitungan Sampel \\
\hline 1. & Tarbiyah dan Keguruan & 1215 & $1215 / 4840 \times 240=60$ \\
\hline 2. & Syari'ah dan Ilmu Hukum & 667 & $667 / 4840 \times 240=33$ \\
\hline 3. & Ushuluddin & 133 & $133 / 4840 \times 240=8$ \\
\hline 4. & Dakwah dan Ilmu Komunikasi & 695 & $695 / 4840 \times 240=34$ \\
\hline 5. & Sains dan Teknologi & 877 & $877 / 4840 \times 240=43$ \\
\hline 6. & Psikologi & 190 & $190 / 4840 \times 240=10$ \\
\hline 7. & Ekonomi dan Ilmu Sosial & 734 & $734 / 4840 \times 240=36$ \\
\hline 8. & Pertanian dan Peternakan & 329 & $329 / 4840 \times 240=16$ \\
\hline & Total Mahasiswa Semester 7 & 4840 & 240 \\
\hline
\end{tabular}

Sumber : UIN Suska 2019

\section{Teknik Pengumpulan Data}

Penelitian ini menggunakan satu set angket yang terbagi ke dalam empat instrumen. Bagian Pertama terdiri dari Informasi tentang Identitas responden, Skala bagian pertama skala perencanaan karir, skala bagian kedua terdiri dari skala efikasi diri, skala bagian ketiga terdiri dari skala regulasi diri, dan skala bagian keempat skala religiusitas. Semua instrumen menggunakan skala rikert. Skala Likert (Likert Scale) yang dikembangkan oleh Rensis Likert adalah variasi yang paling sering digunakan dari skala penilaian yang dijumlahkan. Nilai skala 1 mengindikasikan sikap yang sangat tidak mendukung (sangat tidak setuju). Intensitas lain adalah 2 (tidak setuju), 3 (netral), 4 (setuju) dan 5 (sangat setuju).

\section{Teknik Analisis Data}

1. Statistik Deskriptif

2. Uji Hipotesis

Tahapan analisis yang digunakan dalam pendekatan PLS antara lain:

1. Pengujian Model Pengukuran (Measurement Model)

a. Convergent Validity. Nilai convergen validity adalah nilai loading faktor

b. Discriminant Validity.

c. Composite Reliability dengan indikator reflektif sebagai berikut

Tabel 2 Uji Reliabilitas Konstruk

\begin{tabular}{lll}
\hline Parameter & \multicolumn{1}{c}{ Rule of Thumb } \\
\hline Composite & a. & $>0.70$, untuk confirmary research \\
Reliability & b. & $>0.60-0.70$ masih dapat diterima exsplaratory research \\
\hline Cronbach's & a. & $>0.70$, untuk confirmary research \\
alpha & b. & $>0.60$ masih dapat diterima exsplaratory research \\
\hline
\end{tabular}


2. Pengujian Model Struktural (Inner Model)

a. $\quad R$ Square pada konstruk endogen.

b. $\mathrm{Q}^{2}$ Predictidtive Relevance,

c. Estimate for Path Coefficients,

Tabel 3 Evaluasi Model Struktural

\begin{tabular}{lc}
\hline \multicolumn{1}{c}{ Parameter } & Rule of Thumb \\
\hline R-Square & 0.67 (kuat), 0.33 (moderat) dan 0.19 (lemah). \\
\hline Signifikansi (two tailed) & t-value 1,65 (signifikansi level1 0\%) \\
& t-value 1,95 (signifikansi level 5\%) \\
\hline
\end{tabular}

3. Analisis Koefisien Jalur (Path Analysis)

Analisis jalur dalam penellitian ini adalah efikasi diri dan regulasi diri . Sering juga disebut Variabel intervening, atau variabel antara, yaitu variabel yang mempengaruhi hubungan antara variabel independen dan variabel dependen, tetapi tidak dapat diamati dan diukur, yang sehingga variabel independen tidak langsung mempengaruhi berubahnya atau timbulnya variabel dependen.

\section{Hasil dan Pembahasan}

\section{Responden beradasarkan Fakultas}

Berdasarkan Fakultas, pada Gambar 4.1 bisa dilihat bahwa mahasiswa semsetr 7 yang

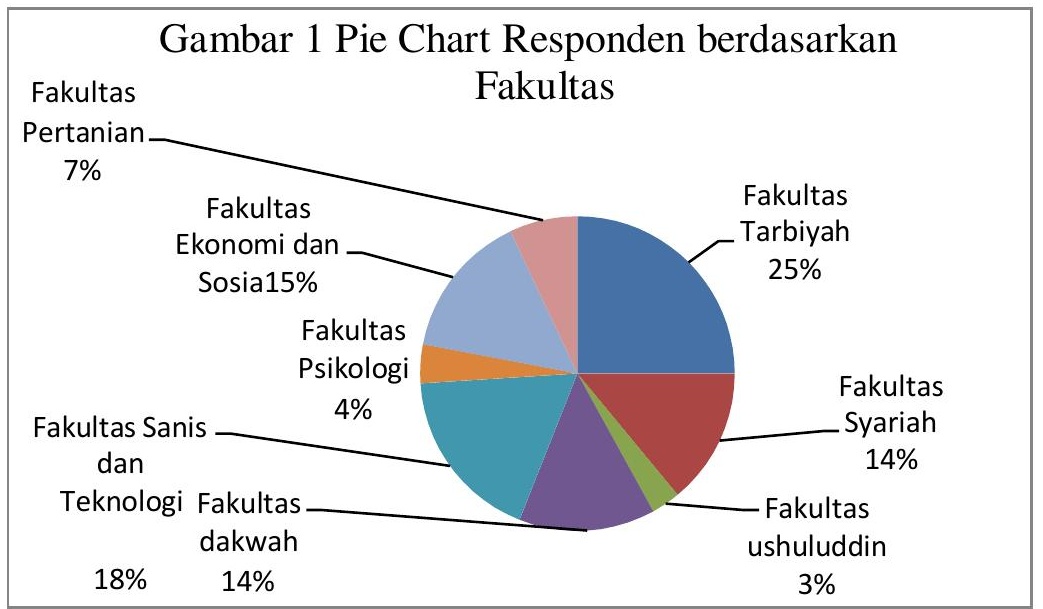


paling banyak secara berurutan adalah dari Fakultas Tarbiyah dan Keguruan (25\%), Fakultas Sains dan Teknologi, (18\%) Fakultas Ekonomi dan Ilmu Sosial (15\%), Fakultas Syariah dan Ilmu Hukum (14\%), Fakultas Pertanian (7\%), dan Fakultas Psikologi (4\%)

\section{Responden Berdasarkan Jenis Kelamin}

Berdasarkan Gambar 1 bisa dilihat bahwa Jumlah responden perempuan dalam penelitian adalah 152 orang atau $63 \%$ dari keseluruhan responden, dan responden laki-laki sebanyak 88 orang atau $37 \%$, dari keseluruhan sampel.

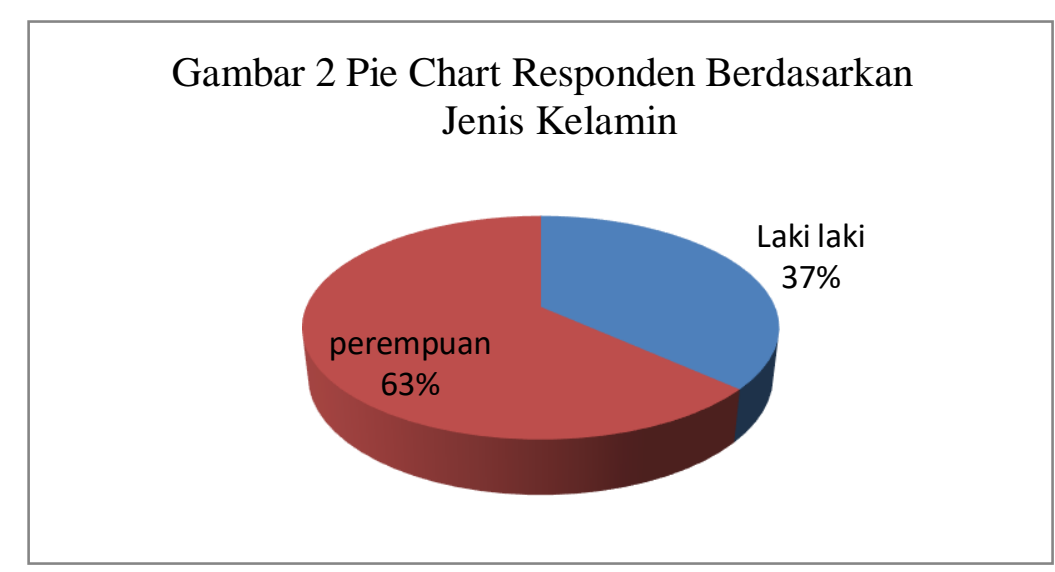

Sumber Data : Primer, 2020

Gambaran Religiusitas Mahasiswa UIN Suska Riau

Tabel 4 Kategori Tingkat Religiusitas Mahasiswa UIN Suska Riau berdasarkan Asal Fakultas

\begin{tabular}{lccc}
\hline \multirow{2}{*}{\multicolumn{1}{c}{ Asal Fakultas }} & \multicolumn{3}{c}{ Kategori } \\
\cline { 2 - 4 } & $\begin{array}{c}\text { Rendah } \\
(<111)\end{array}$ & $\begin{array}{c}\text { Sedang } \\
(111-161)\end{array}$ & $\begin{array}{c}\text { Tinggi } \\
(>161)\end{array}$ \\
\hline Dakwah \& Ilmu Komunikasi & 20.59 & 70.59 & 8.82 \\
\hline Ekonomi dan Ilmu Sosial & 16.67 & 83.33 & - \\
\hline Pertanian dan Peternakan & 17.65 & 82.35 & - \\
\hline Psikologi & - & 100.00 & - \\
\hline Sains dan Teknologi & 4.65 & 93.35 & - \\
\hline Syariah dan Ilmu Hukum & 6.06 & 87.88 & 6.06 \\
\hline Tarbiyah dan Keguruan & 9.84 & 88.52 & 1.64 \\
\hline
\end{tabular}




\begin{tabular}{lccc}
\hline Ushuluddin & 14.29 & 71.43 & 14.29 \\
\hline Persen & 11.25 & 85.83 & 2.92 \\
\hline Jumlah & 27 & 206 & 7 \\
\hline
\end{tabular}

Sumber: Data Olahan

Gambaran Efikasi Diri Mahasiswa UIN Suska Riau

Tabel 5 Kategori Tingkat Efikasi Diri Mahasiswa UIN Suska Riau berdasarkan Asal Fakultas

\begin{tabular}{lccc}
\hline \multirow{2}{*}{ Asal Fakultas } & \multicolumn{3}{c}{ Kategori } \\
\cline { 2 - 4 } & $\begin{array}{c}\text { Rendah } \\
(<\mathbf{6 2})\end{array}$ & $\begin{array}{c}\text { Sedang } \\
\mathbf{( 6 2 - 7 4 )}\end{array}$ & $\begin{array}{c}\text { Tinggi } \\
(>\mathbf{7 5})\end{array}$ \\
\hline Dakwah \& Ilmu Komunikasi & 20.59 & 70.59 & 8.82 \\
\hline Ekonomi dan Ilmu Sosial & 13.89 & 77.78 & 8.33 \\
\hline Pertanian dan Peternakan & 5.88 & 88.24 & 5.88 \\
\hline Psikologi & 11.11 & 77.78 & 11.11 \\
\hline Sains dan Teknologi & 6.98 & 32.56 & 60.47 \\
\hline Syariah dan Ilmu Hukum & 9.09 & 66.67 & 24.24 \\
\hline Tarbiyah dan Keguruan & 9.84 & 80.33 & 9.84 \\
\hline Ushuluddin & - & 57.14 & 42.86 \\
\hline \multicolumn{1}{c}{ Persen } & 26 & 163 & 51 \\
\hline \multicolumn{1}{c}{ Jumlah } & 10.83 & 67.92 \\
\hline Sum & & & 21.25 \\
\hline
\end{tabular}

Sumber: Data Olahan

\section{GambaranPerencanaan Karir Mahasiswa UIN Suska Riau}

Tabel 6 Kategori Tingkat Perencanaan Karir Mahasiswa UIN Suska Riau berdasarkan Asal Fakultas

\begin{tabular}{lccc}
\hline \multirow{2}{*}{ Asal Fakultas } & \multicolumn{3}{c}{ Kategori } \\
\cline { 2 - 4 } & Rendah $(<129)$ & Sedang $(129-152)$ & Tinggi (> 152) \\
\hline Dakwah \& Ilmu Komunikasi & 17.65 & 70.59 & 11.76 \\
\hline Ekonomi dan Ilmu Sosial & 19.44 & 75.00 & 5.56 \\
\hline Pertanian dan Peternakan & 5.88 & 82.35 & 11.76 \\
\hline Psikologi & - & 77.78 & 22.22 \\
\hline Sains dan Teknologi & 9.30 & 76.74 & 13.95 \\
\hline Syariah dan Ilmu Hukum & 3.03 & 81.82 & 15.15 \\
\hline
\end{tabular}




\begin{tabular}{clll}
\hline Tarbiyah dan Keguruan & 6.56 & 68.85 & 24.59 \\
\hline Ushuluddin & 14.29 & 57.14 & 28.57 \\
\hline Persen & 24.00 & 178.00 & 38.00 \\
\hline Jumlah & 10.00 & 74.17 & 15.83 \\
\hline
\end{tabular}

Sumber: Data Olahan

\section{Pengujian dan Analisis Data}

\section{Pengujian Model Pengukuran ( outer model)}

Analisis model pengukuran dibagi kedalam dua bagian yaitu Convergent Validity and Dicscriminant Validity. Tujuan dari pengukuran ini ialah untuk mengukur korelasi antara variabel laten dengan indikatornya.

\section{a. Convergent validity.}

Nilai convergen validity adalah nilai loading faktor pada variabel laten dengan indikatorindikatornya. Convergen validity dinilai berdasarkan korelasi antara item score/compound score dengan construct score yang dihitung dengan PLS. Ukuran reflektif dikatakan tinggi jika berkorelasi lebih dari 0,70 dengan konstruk yang ingin diukur. Namun untuk penelitian tahap awal dari pengembangan skala pengukuran nilai loading 0.50 sampai 0.60 dianggap cukup. Dibawah ini adalah tabel loading factor yang masing-masing indikator dihitung menggunakan PLS.

Proses evaluasi pada convergent validity dibagi kedalam tiga yakni evaluasi individual item reliability, yang dapat dilihat dari hasil standardized loading factor. Nilai loading factor harus lebih besar dari 0.7, hal tersebut dikatakan ideal.

Dari Tabel 4.15 bisa dilihat bahwa dari indikator yang terdiri dari empat variabel tersebut memiliki indikator yang bervariasi. Tidak semua indikator variabel, loading factor nya memberikan nilai yang diatas 0,7 , sehingga dikeluarkan loading factor yang lebih kecil dari 0,7 maka dikeluarkan dari model

Tabel 7 Uji Outer Loading

\begin{tabular}{cccc}
\hline Efikasi Diri & loading & Religiusitas & loading \\
\hline Z1.1 & 0.799 & X1.1 & 0.912 \\
\hline Z1.12 & 0.814 & X1.10 & 0.901 \\
\hline Z1.13 & 0.840 & X1.11 & 0.946 \\
\hline Z1.14 & 0.829 & X1.13 & 0.900 \\
\hline
\end{tabular}




\begin{tabular}{cccc}
\hline Z1.15 & 0.864 & X1.18 & 0.837 \\
\hline Z1.2 & 0.778 & X1.19 & 0.719 \\
\hline Z1.3 & 0.749 & X1.20 & 0.936 \\
\hline Perencanaan Karir & loading & X1.22 & 0.940 \\
\hline Y24 & 0.802 & X1.23 & 0.945 \\
\hline Y42 & 0.819 & X1.24 & 0.714 \\
\hline Y6 & 0.859 & X1.29 & 0.837 \\
\hline Y7 & 0.876 & X1.3 & 0.932 \\
\hline & & $X 1.30$ & 0.818 \\
\hline & & $X 1.4$ & 0.962 \\
\hline & & $X 1.5$ & 0.967 \\
\hline & & $X 1.6$ & 0.955 \\
\hline
\end{tabular}

Dari hasil pada Tabel 7 semua indikator sudah menunjukkan outer laoding $>0,7$. Berarti indikator yang dipergunakan dalam penelitian ini adalah valid atau telah memenuhi convergent validity. Selain itu untuk melihat convergen validity dapat melhat nilai cross laoding dari discriminant validity dimana diharapkan korelasi terbesar suatu variable dibentuk dari pertanyaan yang membentuknya.

\section{b. Discriminant Validity.}

Dicscriminant validity dapat dievaluasi dari hasil nilai square root of AVE dibandingkan dengan nilai korelasi satu konstruk dengan konstruk lainnya. Dicscriminant validity ajuga dapat dievaluasi dari nilai cross loading setiap indikator yang harus lebih besar dari 0,7. Dalam diskriminant validity yaitu membandingkan antara nilai loading daripada konstruks yang satu dengan konstruk yang lainnya. Dalam membandingkan hal tersebut nilai loading dari konstruk yang dituju harus lebih besar daripada nilai loading konstruk yang lain. Berikut adalah hasil pengujian dari discriminant validity

Tabel 8 Nilai Cross Loading

\begin{tabular}{cccc}
\hline & Efikasi Diri & Perencanaan Karir & Religositas \\
\hline 1.1 & 0.799 & 0.568 & 0.547 \\
\hline 1.12 & 0.814 & 0.603 & 0.526 \\
1.13 & 0.840 & 0.613 & 0.562 \\
\hline
\end{tabular}




\begin{tabular}{|c|c|c|c|}
\hline 1.14 & 0.829 & 0.570 & 0.496 \\
\hline 1.15 & 0.864 & 0.668 & 0.644 \\
\hline 1.2 & 0.778 & 0.524 & 0.448 \\
\hline 1.3 & 0.749 & 0.591 & 0.648 \\
\hline 2.30 & 0.660 & 0.668 & 0.659 \\
\hline 2.31 & 0.660 & 0.645 & 0.615 \\
\hline 2.7 & 0.595 & 0.674 & 0.506 \\
\hline 2.9 & 0.664 & 0.706 & 0.524 \\
\hline 24 & 0.607 & 0.802 & 0.634 \\
\hline 42 & 0.602 & 0.819 & 0.534 \\
\hline 6 & 0.639 & 0.859 & 0.618 \\
\hline 7 & 0.608 & 0.876 & 0.545 \\
\hline 1.1 & 0.636 & 0.635 & 0.912 \\
\hline 1.10 & 0.596 & 0.583 & 0.901 \\
\hline 1.11 & 0.625 & 0.651 & 0.946 \\
\hline 1.13 & 0.575 & 0.618 & 0.9 \\
\hline 1.18 & 0.637 & 0.682 & 0.837 \\
\hline 1.19 & 0.558 & 0.535 & 0.719 \\
\hline 1.20 & 0.611 & 0.645 & 0.9 \\
\hline 1.22 & 0.666 & 0.684 & 0.940 \\
\hline 1.23 & 0.647 & 0.655 & 0.945 \\
\hline 1.24 & 0.539 & 0.547 & 0.714 \\
\hline 1.29 & 0.573 & 0.576 & 0.837 \\
\hline 1.3 & 0.649 & 0.655 & 0.932 \\
\hline 1.30 & 0.567 & 0.548 & 0.818 \\
\hline 1.4 & 0.651 & 0.638 & 0.962 \\
\hline
\end{tabular}




\begin{tabular}{lccc}
\hline & 0.654 & 0.640 & 0.967 \\
1.5 & & & 0.955 \\
1.6 & 0.634 & 0.621 & 0.926 \\
\hline 1.9 & 0.624 & 0.631 & \\
\hline
\end{tabular}

Sumber: Output SmartPLS 3.28

Pengukuran ini dapat dikatakan untuk mengukur reliabilitas component score variable laten dan hasilnya lebih konservatif dibandingkan dengan composite reliability (pc). Direkomendasikan nilai AVE harus lebih besar dari 0.50.

Tabel 9 Average Variance Extracted (AVE)

\begin{tabular}{cc}
\hline Variabel & Average Variance Extracted (AVE) \\
Efikasi Diri & 0,658 \\
Perencanaan Karir & 0,705 \\
Religositas & 0,800 \\
\hline Sumber: Output SmartPLS 3.28
\end{tabular}

Dari Tabel 9 dapat dilihat bahwa nilai AVE nya sudah diatas 0,5 hal ini berarti bahwa pada semua variabel laten yang dipergunakan dalam penelitian ini valid karena sudah memenuhi nilai AVE yang di rekomendasikan (>0.5).

Dengan demikian disimpulkan data dalam penelitian ini memenuhi aturan validitas dari sisi kelayakan convergent validity, Discriminant validity dan Average Variance Extracted (AVE)

\section{c. Composite Reliability dan Cronbach Alpha $>0.7$}

Nilai dari composite reliability dan cronbach's alpha harus lebih besar dari 0,7 meskipun nilai 0,6 masih dapat diterima.

Tabel 10 Composite Reliability Dan Cronbach Alpa

\begin{tabular}{lcc}
\hline & Cronbach's Alpha & Composite Reliability \\
\hline Efikasi Diri & 0,913 & 0,931 \\
\hline Perencanaan Karir & 0,860 & 0,905 \\
\hline Religositas & 0,984 & 0,985 \\
\hline
\end{tabular}

Sumber: Output SmartPLS 3.28

Konstruk dinyatakan reliabel jika memiliki nilai composite reliability di atas 0,70 dan cronbach's alpha di atas 0,60. Dari hasil output SmartPLS pada Tabel di atas menunjukkan bahwa seluruh konstruk memiliki nilai composite reliability di atas 0,70 dan cronbach's alpha di atas 0,60. Jadi dapat disimpulkan bahwa konstruk memiliki reliabilitas yang baik. 


\section{Pengujian Model Struktural ( Inner Model)}

Model struktural dalam PLS dievaluasi dengan menggunakan $\mathrm{R}^{2}$ untuk konstruk dependen, nilai koefisien path atau t-values tiap path untuk uji signifikansi antarkonstruk dalam model struktural. Menurut Chin nilai R square sebesar 0.67 (kuat), 0.33 (moderat) dan 0.19 (lemah). Perubahan nilai R-square dapat digunakan untuk menilai pengaruh substantif variabel laten independen tertentu terhadap variabel laten dependen.

Gambar 3 Pengujian Model Struktural ( Inner Model)

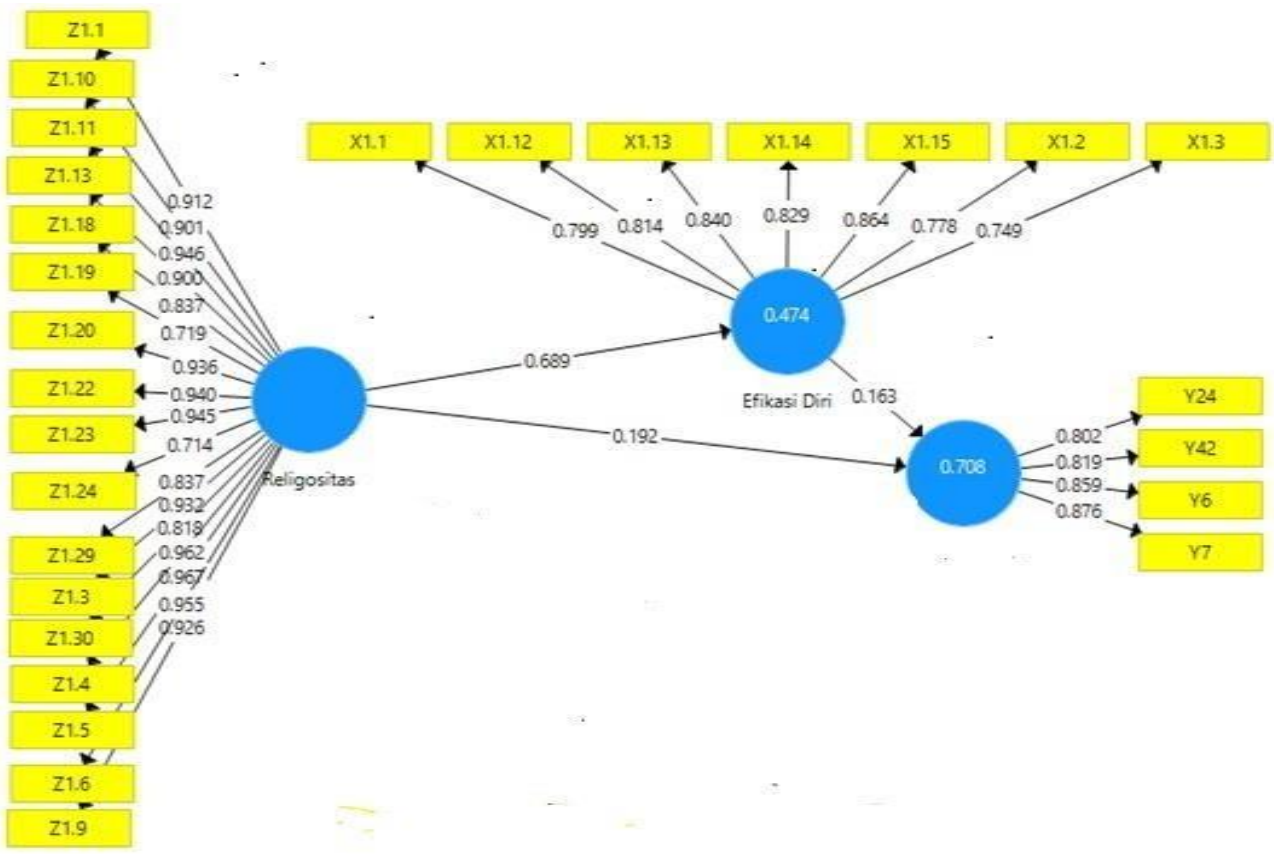

Model struktural dievaluasi dengan menggunakan $R$-square untuk variabel dependen dan nilai koefisien path untuk variabel independen yang kemudian dinilai signifikansinya berdasarkan nilai t-statistic setiap path.

\section{a. Kefisien Determinasi (R Square)}

Nilai R Square adalah koefisien determinasi pada konstruk endogen. Menurut Chin (1998), nilai R square sebesar 0.67 (kuat), 0.33 (moderat) dan 0.19 (lemah).

Tabel 11 R Square dan R Square Adjusted

\begin{tabular}{lrrc}
\hline & \multicolumn{2}{c}{ R Square } & R Square Adjusted \\
\hline Efikasi Diri & & 0. & 0.472 \\
\hline
\end{tabular}




\begin{tabular}{llll}
\hline Perencanaan Karir & & 0. & 0.705 \\
& 708 & & \\
\hline
\end{tabular}

Sumber: Output SmartPLS 3.28 hasil diolah oleh peneliti.

\section{b. Stone-Geisser Q-square test (Predictive Relevance )}

Nilai $Q$-square lebih besar 0 (nol) menunjukkan bahwa model mempunyai nilai predictive relevance, sedangkan nilai $Q$-square kurang dari 0 (nol) menunjukkan bahwa model kurang memiliki predictive relevance.

Untuk menghitung $\mathrm{Q}_{2}$ dapat digunakan rumus:

$\mathrm{Q}^{2}=1-\left(1-\mathrm{R} 1^{2}\right)\left(1-\mathrm{R} 2^{2}\right) \ldots \ldots\left(1-\mathrm{Rp}^{2}\right) \ldots$

Nilai $\mathrm{Q}^{2}=1-(1-0.474)(1-0.496)=0,846$. Nilai $Q$-square lebih besar dari 0 (nol) menunjukkan bahwa model mempunyai nilai predictive relevance.

\section{c. Goodness of Fit (gof)}

Evaluasi Goodness of Fit model diukur menggunakan $\mathrm{R}^{2}$ variabel laten dependen dengan interpretasi yang sama dengan regresi.

$$
G o F=\sqrt{\overline{A V E} \times \overline{R^{2}}}
$$

Gof= 0,465 gofnya sudah besar karena di atas 0,38.

\section{Pengujian Hipotesis}

Tabel 12 Pengujian Hipotesa dari Path Coefficient

\begin{tabular}{lccrll}
\hline Hubungan & $\begin{array}{l}\text { Original } \\
\text { Sample }(\mathrm{O})\end{array}$ & $\begin{array}{l}\text { T Statistics } \\
(|\mathrm{O} / \mathrm{STDEV}|)\end{array}$ & P Values & Keputusan & Kesimpulan \\
\hline $\begin{array}{l}\text { Religiusitas-> Efikasi } \\
\text { Diri }\end{array}$ & 0.689 & 14.066 & 0.000 & $\begin{array}{l}\text { Tolak Ho, } \\
\text { Terima H1 }\end{array}$ & $\begin{array}{l}\text { berpengaruh } \\
\text { langsung }\end{array}$ \\
$\begin{array}{l}\text { Efikasi Diri -> } \\
\text { Perencanaan Karir }\end{array}$ & 0.163 & 2.564 & 0.005 & $\begin{array}{l}\text { Tolak Ho } \\
\text { Terima H1 }\end{array}$ & $\begin{array}{l}\text { berpengaruh } \\
\text { langsung }\end{array}$ \\
\hline $\begin{array}{l}\text { Religositas -> } \\
\text { Perencanaan Karir }\end{array}$ & 0.192 & 3.160 & 0.001 & $\begin{array}{l}\text { Tolak Ho } \\
\text { Terima H1 }\end{array}$ & $\begin{array}{l}\text { berpengaruh } \\
\text { langsung }\end{array}$ \\
\hline
\end{tabular}

Berdasarkan pada Tabel 12 dapat dilakukan Intrepetasi terhadap hasil pengujian hipotesis 
yang diperoleh sebagai berikut:

1. Pengujian hipotesis pertama : Religiusitas berpengaruh langsung dan signifikan positif terhadap Efikasi Diri

Religiusitas berpengaruh langsung dan signifikan positif terhadap Efikasi Diri dengan koefisien sebesar 0.689 dengan nilai $t$ stat $=14.066>t$ tabel $=1,64$ dan nilai prob.value $=0.000<$ alpa $=0.05$. al ini berarti variabel religiusitas berpengaruh langsung positif terhadap perencanaan karir dan singinifikan terhadap perencanaan karir.

2. Pengujian Hipotesis ke dua, efikasi diri berpengaruh langsung dan signifikan prositif terhadap Perencanaan Karir

Efikasi Diri berpengaruh langsung dan signifikan prositif terhadap Perencanaan Karir dengan koefisien sebesar 0.163 dengan nilai $\mathrm{t}$ stat $=2.564>\mathrm{t}$ tabel $=1,64$ dan nilai prob.value $=0.005<$ alpa $=0.05$. Hal ini berarti variabel efikasi diri berpengaruh langsung berpengaruh positif (angka 0,.163yang positif) terhadap perencanaan karir dan singinifikan terhadap perencanaan karir yaitu sebesar 2.564

3. Religiusitas berpengaruh langsung dan signifikan prositif terhadap Perencanaan Karir Religiusitas berpengaruh langsung dan signifikan positif terhadap perencanaan karir dengan koefisien sebesar $\quad 0.192$ dengan nilai $\mathrm{t}$ stat $=3.160>\mathrm{t}$ tabel $=1,64$ dan nilai prob.value $=0.001<$ alpa $=0.05$. Hal ini berarti religiusitas berpengaruh positif (angka 0,192 yang positif ) dan singinifikan terhadap variabel perencanaan karir yaitu sebesar 3.160. Bagi individu yang telah bekerja, individu yang memiliki dukungan sosial yang suportif dari komunitas keagamaan lebih mampu mengatasi masalah ketika individu tersebut mengalami stress kerja atau kehilangan pekerjaan. Individu tersebut lebih sedikit mengalami depresi dan tidak kehilangan harapan .

4. Religiusitas berpengaruh tidak langsung dan signifikan positif terhadap Perencanaan Karir melalui Efikasi Diri dengan koefisien sebesar 0.112 dengan $\mathrm{t}$ stat=2.495 > t tabel=1.64 dan nilai prob.value $=0.006<$ alpa=0.05. Ini bisa dilihat pada berikut .

Tabel 13 Pengaruh efikasi diri sebagai Variabel Intervening

\begin{tabular}{|c|c|c|c|c|}
\hline $\begin{array}{l}\text { Hubungan } \\
\text { Langsung }\end{array}$ & $\begin{array}{l}\text { Original } \\
\text { Sample (O) }\end{array}$ & $\begin{array}{l}\text { T Statistics P Values } \\
(|\mathrm{O} / \mathrm{STDEV}|)\end{array}$ & Keputusan & Kesimpulan \\
\hline $\begin{array}{l}\text { Religiusitas -> Efikasi } \\
\text { Diri -> Perencanaan } \\
\text { Karir }\end{array}$ & 0.112 & 0.006 & $\begin{array}{l}\text { tolak } \mathrm{Ho} \text {, } \\
\text { Terima } \mathrm{Ha}\end{array}$ & $\begin{array}{l}\text { berpengaruh } \\
\text { tdk langsung }\end{array}$ \\
\hline
\end{tabular}


Berdasarkan Tabel 13, bisa diambil kesimpulan, bahwa: 1) Religiusitas berpengaruh tidak langsung dan signifikan positif terhadap Perencanaan Karir melalui Efikasi Diri dengan koefisien sebesar 0.112 dengan $\mathrm{t}$ stat $=2.495>\mathrm{t}$ tabel $=1.64$ dan nilai prob.value $=0.006<$ alpa=0.05. Hal ini berarti kenaikan 1 poin religiusitas akan meningkatkan perencanna karir secara tidak langsung melalui efikasi diri sebagai variabel mediasi/intervening sebesar 0.112 poin dengan asumsi variable lain konstan.

\section{PENUTUP}

\section{Kesimpulan dan Saran}

Penelitian ini memperlihatkan pengaruh efikasi diri dan religiusitas terhadap perencanaan karir Mahasiswa UIN Suska Riau. Terdapat dua hubungan yaitu hubungan langsung dan tidak langsung. Pengaruh langsung dilihat antara variabel bebas religiusitas terhadap variabel tidak bebas perencanaan karir, dan pengaruh langsung variabel efikasi diri terhadap perencanaan karir mahasisawa UIN Suska Riau. Pengaruh tidak langsung yaitu pengaruh religiusitas melalui efikasi diri terhadap perencanaan karir mahasiswa UIN Suska Riau.

Pengaruh antar variabel yang diteliti adalah : pertama terdapat pengaruh positif religiusitas terhadap efikasi diri mahasiswa UIN Suska Riau. Kedua, terdapat pengaruh postifif efikasi diri terhadap perencanaan karir mahasiswa UIN Suska Ketiga terdapat pengaruh positif religiusitas terhadap perencanaan Karir mahasiswa Uin Suska. Ke empat terdapat pengaruh positif tidak langsung religiusitas melalui efikasi diri terhadap perencanaan karir mahasiswa UIN Suska Riau. Dan berdasarkan pengolahan data secara deskriptif, kategori religisuitas, efikasi diri dan perencanaan karir mahasiswa UIN Suska adalah kategori sedang.

Dalam upaya meningkatkan perencanaan karir mahasiswa UIN Suska diperlukan peningkatan kemampuan akademik berupa kurikulum kurikulum pendidikan yang menitikberatkan kepada peningkatan kemampuan dan kompetensi yang dibutuhkan oleh pasar kerja saat ini, peningkatan konsep diri berupa religiusitas, efikasi diri, dan perencanaan karir. Khususnya untuk dosen yang mengampu mata kuliah yang berkaitan dengan ketiga varibel dalam penelitian ini, agar mendorong mahasiswa UIN Suska memliki karakter yangkuat dari ketiga variabel tersebut. Penelitian ini memilkiki maknaintegrasi terhadap keilmuan.

Kepada mahasiswa semester 7 diminta membuat dan menuliskan tindakan nyata nya 
dalam perencanaan karir, dengan dibnatu oleh para dosen untuk mengembangkan dan meningkatkan potensi dan sumberdaya keahlian yang dimiliki. Potensi soft skill dan hard kill dan kemampuan kemampuan lain yang dibutuhkan harus diasah sedemikian rupa, sehingga ketika menyelesaikan pendidikan di UIN Suska, memliiki persiapan yang memadai menghadapi persaingan kerja dan kehidupan paska kuliah.

\section{DAFTAR PUSTAKA}

Abdillah, Willy \& Jogiyanto Hartono, Partial Least Square (PLS) Alternatif StructuralEquation Modeling (SEM) dalam Penelitian Bisnis, (Yogyakarta: ANDI, 2015)

Abdul Azis Ahyadi, Psikologi Agama: Kepribadian Muslim Pancasila, Cet. V, (Bandung: Sinar Baru Algensindo, 2005

Achmad Gholib, MA . Study Islam, Pengantar Memahami Agama, al-Qur'an al Hadits dan Sejarah Peradaban Islam. (Jakarta, Faza Media:2006)

Albert Bandura, "Self-efficacy in Changing Societies", (New York:Cambridge University press, 1995)

Albert Bandura and Dale H. Schunk, "Cultivating Competence, self efficacy and Intrinsic Interest Thugh Proximal Self Motivation", Journal of Personality and Social Psychology, (Vol 41 No 3, 1981)

Albert Bandura, "Human Agency in Social Cognitive Theory Americans Psycologist", Journal ofPersonality and Social Psycchology, (vol. 44, No. 9, 1989).

Atkinson, J.W, Pengantar Psikologi (Terjemah Nurdjanah dan Rukmini), Jakarta: Erlangga, 1995)

Ball, Ben. Assessing Your Career: Time For Change., (Yogyakarta: Kanisius, 1997)

Djamaluddin Ancok dan Fuad Nashori Suroso, Psikologi Islami, Yogyakarta Pelajar`2005

Donald R. Cooper \& Pamela S. Schindler, Metode Penelitian Bisnis, (Jakarta: Salemba Empat, 2017), hlm. 327.

Duffy, R. D., \& Sedlacek, W. E. (2010). The salience of a career calling among college students: Exploring group differences and links to religiousness, life meaning, and life satisfaction. The Career Development Quarterly, 59(1), 27-41. https://doi.org/10.1002/j.21610045.2010.tb00128.x 
Feist, J \& Feist, G. J.. Teori Kepribadian, edisi 7.,( Jakarta: Salemba Humanika),

Fetzer Institute, 2003. National Institute on Aging Working Group: Multidimensional Measurement of Religiousness, Spirituality for Use in Health Research. A Report ofa National Working Group. Supported by the Fetzer Institute in Collaboration with the National Institute on Aging. Kalamazoo, MI: Fetzer Institute https://edukasi.kompas.com/read/2016/04/23/17424071/Kenapa.Lulusan.Perguruan.Tinggi. Maki n.Susah.Mendapat.Pekerjaan.

https://uin-suska.ac.id/sistem-studi-mahasiswa/kurikulum-dan-kompetensi/

Herimanto, Ilmu Sosial \& Budaya Dasar, (Jakarta: PT. Bumi Aksara. 2010),

Hurlock, E. B. Psikologi perkembangan. suatu pendekatan sepanjang rentang kehidupan diterjemahkan dari terjemahan Bahasa Inggris oleh Istiwidayanti dan Soedjarwo ( Jakarta: Erlangga , 1991),

I Ghozali Structural equation modeling: Metode alternatif dengan partial least square $(p l s)$ - 2008 - (Badan Penerbit Universitas Diponegoro, 2008),

Kaswan. Career Development, ( Bandung: Alfabeta, 2014),

Khairul Amri Wicaksono, Hubungan antara self Efficatcy dengan self Regulation dengan perencanaan Karir pada Mahasiswa Semester 8 UNS Semaranf, Skripsi, 2015

Marliany R, Hubungan antara Religiusitas dengan Prestasi Belajar pada Mahasiswa Fakultas Syariah dan Hukum UIN Sunan Gunung Djati Bandung, Jurnal Psikologi Integratif, Vol 4, Nomor 2, 2016

McCullough, M.E., \& Willoughby, L.B, Religion, Self -Regulation, and Self- Control: Associations, Explanations, and Implications. Psychological Bulletin,Vol. 135, No. 1, 69-93. Tahun 2009, American Psychologica 1 Association,http://www.psy.miami.edu/faculty/ mmccullough /Papers/Relig_self_control_bulletin.pdf, diunduh November 2019.

Mondy, Judy Bandy. 2008. Manajemen Sumber Daya Manusia. (Jakarta: Erlangga)

Nuryaman \& Veronica Christina, Metodologi Penelitian Akuntansi dan Bisnis, ( Bogor: Ghalia Indonesia, 2015), Rois Mahfud, Al-Islam Pendidikan Agama Islam, (Palangkaraya: Erlangga, 2011),

Sanjaya, Wina, Perencanaan dan Desain Sistem Pembelajaran, (Jakarta:Prenadamedia, 2013),Simamora, Henry. Manajemen Sumber Daya Manusia. Yogyakarta :YKPN. (2011),

Taib Thahir Abdul Mu'in, Ilmu Kalam, (Jakarta: Wijaya, 1992), 
Tikrar Quran Hafalan Tajwid dan Terjemah, (Bandung: Sygma Creative Media Corp: 2017) 